\title{
As responsabilidades solidária e subsidiária no federalismo brasileiro: contextualização em matéria de saúde e posicionamento do Supremo Tribunal Federal
}

Solidarity and subsidiary responsibilities in Brazilian federalism: contextualization in health matters and position of the Federal Supreme Court

Responsabilidades solidarias y subsidiarias en el federalismo brasileño: contextualización en materia de salud y posición de la Corte Suprema Federal

Moacyr Rey Filho 1

Sylvia Patrícia Dantas Pereira²

\section{Resumo}

Objetivo: o artigo analisa a distinção entre responsabilidade solidária e subsidiária dos entes federativos para prestação de ações e serviços de saúde e contribui com a indicação de critérios objetivos para a fixação dessas responsabilidades. Metodologia: foram verificados os dispositivos constitucionais e legais, trazendo-se a divergência doutrinária e o posicionamento do Supremo Tribunal Federal (STF) quanto à fixação da responsabilidade dos entes federativos como solidária. Resultados: as discussões devem se aprofundar para que a responsabilidade subsidiária dos entes federados seja determinada segundo critérios objetivos de descentralização, regionalização e hierarquização definidos pelos gestores do Sistema Único de Saúde (SUS). Conclusão: necessidade que o STF avalie mais detidamente o modelo de governança do SUS, constituído por regras infraconstitucionais próprias, que trazem a autonomia dos entes federados para disciplinar suas atribuições na proteção e concretização do direito à saúde.

Palavras-chave: Federalismo. Sistema de saúde. Sistema de justiça.

\begin{abstract}
Objective: the article analyzes the distinction between joint and several liability of federative entities for the provision of health actions and services and contributes to the indication of objective criteria for the establishment of these responsibilities. Methodology: the constitutional and legal provisions were verified, bringing the doctrinal divergence and the position of the Supreme Court regarding the establishment of the responsibility of the federative entities as solidary. Results: the discussions should deepen so that the subsidiary responsibility of the federated entities is determined according to objective criteria of decentralization, regionalization and hierarchization defined by the Brazilian Unified Health System (SUS) managers. Conclusion: it is necessary for the Supreme Court to evaluate more closely the SUS governance model, constituted by its own unconstitutional rules, which

\footnotetext{
${ }^{1}$ Mestre em Direito e Políticas Públicas pela UniCEUB; professor de Direito da Saúde, Direito Penal e Direito Penal Econômico; promotor de Justiça do Ministério Público do Distrito Federal e Territórios, Brasília, DF, Brasil. E-mail: moacyr.rey.filho@gmail.com

2 Graduada em Farmácia e Direito; farmacêutica do Núcleo de Demandas judiciais, Secretaria de Estado da Saúde Pública do Rio Grande do Norte, Natal, RN, Brasil. E-mail: sylvia.dantas1976@gmail.com
} 
bring the autonomy of the federated entities to discipline their duties in the protection and implementation of the right to health.

Keywords: Federalism. Health System. Justice System.

\section{Resumen}

Objetivo: El artículo analiza la distinción entre la responsabilidad solidaria y solidaria de las entidades federativas por la provisión de acciones y servicios de salud y contribuye a la indicación de criterios objetivos para el establecimiento de estas responsabilidades. Metodología: se verificaron las disposiciones constitucionales y legales, trayendo la divergencia doctrinal y la posición de la Corte Suprema con respecto al establecimiento de la responsabilidad de las entidades federativas como solidarias. Resultados: las discusiones deberían profundizarse para que la responsabilidad subsidiaria de las entidades federadas se determine de acuerdo con criterios objetivos de descentralización, regionalización y jerarquización definidos por los administradores del Sistema Único de la Salud (SUS). Conclusión: es necesario que la Corte Suprema evalúe más de cerca el modelo de gobernanza del SUS, constituido por sus propias normas inconstitucionales, que otorgan la autonomía de las entidades federadas para disciplinar sus deberes en la protección e implementación del derecho a la salud.

Palabras clave: Federalismo. Sistema de salud. Sistema de justicia.

\section{Introdução}

A questão sobre a responsabilidade solidária dos entes da federação para prestação de ações e serviços públicos de saúde gera grandes debates entre os doutrinadores do direito sanitário e nos tribunais, especialmente no Supremo Tribunal Federal (STF), órgão responsável pela palavra final no sistema de justiça.

Apesar dessa discussão, ainda não se encontra, na jurisprudência consolidada do STF, critérios objetivos para a fixação da responsabilidade solidária ou subsidiária de cada ente federativo, segundo o quadro normativo constitucional e infranconstitucional, bem como de acordo com a pactuação feita entre esses entes.

O presente visa artigo visa contribuir, ainda que de forma inicial, com o esclarecimento da distinção entre responsabilidade solidária e subsidiária de cada ente federativo, e ainda, com a indicação de critérios objetivos para fixação dessas responsabilidades, especialmente os conceitos de descentralização, regionalização e hierarquização, termos próprios do sistema de saúde. Tais critérios promovem a integração entre o sistema de justiça e o sistema de saúde.

Dessa forma, foram analisados os (i) dispositivos constitucionais que fixam a repartição de competências administrativa e legislativa em matéria de saúde, ressaltando- 
se os argumentos contrários e favoráveis à responsabilidade solidária dos entes federativos; (ii) o posicionamento do STF sobre a responsabilidade dos entes da Federação na execução de ações e serviços de saúde; e (iii) as diretrizes da descentralização, regionalização e hierarquização como critérios objetivos da responsabilidade sanitária solidária e/ou subsidiária dos entes da Federação.

\section{Competência administrativa e legislativa em matéria de saúde}

A autonomia dos entes federados manifesta-se na repartição de competências constitucionais administrativas e legislativas. Essa distribuição de competências é norteada na Constituição da República Federativa Brasileira (CRFB) de 1988 pelo chamado princípio da predominância de interesse, segundo o qual caberá à União cuidar de matérias e questões predominantemente de interesse geral ou nacional. Os Estados devem atuar e legislar predominantemente sobre assuntos de interesse regional e, finalmente, os Municípios atuam e editam normas em questões de interesse local (1).

A competência administrativa divide-se em competência exclusiva e competência comum: i) a CRFB enumera - taxativa, mas não exaustivamente - as competências exclusivas da União (art. 21) e dos Municípios (Art. 30, incisos III a IX) (2). Já os Estadosmembros detêm as competências que não lhes sejam vedadas pela Constituição, ou seja, aos Estados são reservadas todas as competências administrativas que não sejam exclusivas da União e dos Municípios (art. 25, § $1^{\circ}$ ); e ii) as competências administrativas comuns são aquelas elencadas no art. 23 da CRFB e devem ser exercidas de forma cumulativa entre União, Estados, Distrito Federal (DF) e Municípios (3).

As competências constitucionais legislativas são classificadas em: (i) competências privativas da União (art. 22) (2), as quais podem ser delegadas, mediante lei complementar, aos Estados (art. 22, § único) e ao DF (art. 32, § 1ํ) (2); e (ii) competências concorrentes, para edição de normas pela União, Estados e DF (art. 24) (2). No âmbito da legislação concorrente, a competência da União limita-se ao estabelecimento de normas gerais.

Os Municípios, por sua vez, detêm (iii) competências legislativas exclusivas (art. 30, I) e (iv) competência suplementar (art. 30, II) (2). Assim como as competências administrativas, os Estados-membros possuem competências legislativas remanescentes, isto é, aquelas que não sejam privativas da União e exclusivas dos Municípios (art. 25, § 1ํ) 
(2). Por fim, importante lembrar que ao DF são atribuídas as competências legislativas reservadas aos Estados e Municípios (art. 32, § 1ํ) (2).

O art. 22 da CRFB (2) não elenca nenhuma competência legislativa privativa da União para regular ações e serviços de saúde. Entretanto, o art. 24 dispõe que compete à União, aos Estados e ao DF legislar concorrentemente sobre proteção e defesa da saúde (inciso XII) (2).

Dessa forma, na defesa e proteção do direito à saúde, caberá à União, Estados e DF editarem normas de forma concorrente. A competência da União se restringe à edição de normas gerais, diretrizes e princípios essenciais (art. $24, \S^{1}{ }^{\circ}$ ) (2). Nesse caso, temos, como exemplos, a própria Lei Orgânica do SUS (Lei no 8.080/90) (4) e a Lei nº 8.142/90 (5).

A competência da União para legislar sobre normas gerais não exclui a competência suplementar dos Estados (art. 24, $\S 2^{\circ}$ ) (2). Caso não exista lei federal sobre normas gerais, os Estados e DF podem exercer sua competência legislativa plena, para atender a suas peculiaridades (art. 24, $\S^{\circ}$ ) (2). A superveniência de lei federal sobre normas gerais suspende a eficácia da lei estadual, no que lhe for contrário (art. 24, § 4ํ) (2).

Já a competência legislativa dos Municípios em matéria de saúde será exclusiva quando se tratar de assuntos de interesse local (art. 30, I) (2) e suplementar, quando houver legislação federal ou estadual sobre a questão de saúde (art. 30, II) (2). A expressão interesse local é de difícil conceituação, mas pode ser entendida como decorrente dos interesses diretamente relacionados às necessidades imediatas do Município, mesmo que, secundariamente, atinjam interesses regionais (Estados) ou geral/nacional (União). $\mathrm{Na}$ maioria das hipóteses, somente no caso concreto é que se poderá verificar qual o interesse predominante (6).

Questão que se mostra ainda mais complexa diz respeito à responsabilidade dos entes federados para execução/prestação de ações e serviços de saúde. Nesse caso, tratase de competência administrativa e não apenas legislativa. Podemos concluir, contudo, que se a CRFB (2) atribui uma competência administrativa a qualquer dos entes federados, por consequência lógica, dota esses mesmos entes de competência legislativa para normatizar suas atribuições executivas. É interessante reparar o paralelismo existente entre as competências administrativas exclusivas da União, elencadas no art. 21, e suas competências legislativas privativas, enumeradas no art. 22 (2). 
Com relação à competência para execução de ações e serviços de saúde no Brasil, pode-se afirmar que essa responsabilidade é comum e solidária à União, Estados, DF e Municípios? Para responder a essa pergunta, temos que analisar detidamente a competência administrativa (executiva) comum, prevista no art. 23 da CRFB (2).

De todas as competências administrativas citadas no rol do referido artigo, apenas no inciso II consta a referência "cuidar da saúde e assistência pública, da proteção e garantia das pessoas portadoras de deficiência". Não há, portanto, nenhum outro inciso que traga menção à execução, direta ou indireta, de ações e serviços de saúde.

Assim, aqueles que sustentam que a responsabilidade dos entes federados para prestação de ações e serviços de saúde é solidária, o fazem com base nesse inciso II do art. 23, o qual traz a competência administrativa comum à União, Estados, DF e Municípios. Em sentido contrário, argumenta-se que o referido inciso diz respeito, única e exclusivamente, aos cuidados e proteção da saúde das "pessoas portadoras de deficiência". Vamos analisar os dois posicionamentos.

Ausência de responsabilidade solidária entre os entes federados para execução de ações e serviços de saúde

Como uma das políticas públicas sociais e econômicas, a CRFB (2) instituiu o Sistema Único de Saúde (SUS), organizado como uma rede regionalizada e hierarquizada, para execução de ações e serviços públicos de saúde, na forma de um sistema único, organizado de acordo com a diretriz da descentralização, com direção única em cada esfera de governo. Conclui-se, portanto, que há apenas um sistema, mas com repartições de atribuições e direção única em cada nível governamental federal, estadual, distrital e municipal.

A finalidade da descentralização, especialmente no nível municipal, é fazer com que as ações e serviços de saúde atendam, de forma mais próxima e efetiva, as necessidades locais da população e os fatores condicionantes específicos do seu território, facilitando assim o acesso a essas ações e serviços, bem como buscando sua maior resolutividade, por meio de uma administração mais moderna e participativa (7).

Nesse sentido, como já mencionado, a CRFB enumera, taxativa, mas não exaustivamente, as competências administrativas (executivas) exclusivas dos Municípios (Art. 30, incisos III a IX) (2). Em matéria de proteção ao direito à saúde, a CRFB estabeleceu, como competência administrativa exclusiva, que cabe aos Municípios prestar, com 
a cooperação técnica e financeira da União e do Estado, serviços de atendimento à saúde da população (Art. 30, inciso VII) (2).

Alega-se que a competência administrativa comum dos entes federativos não gera a responsabilidade solidária para a execução direta de ações e serviços de saúde. A responsabilidade da União e dos Estados restringe-se à cooperação técnica e financeira e à execução suplementar ou complementar de algumas ações e serviços de saúde, mas não à execução direta de todas as ações e serviços do SUS. Nesse sentido, Arretche (8) afirma que

a implementação da descentralização pretende, dentre outros propósitos: "(i) transferir aos governos locais (Estados e Municípios) as funções de gestão dos atos e procedimentos médicos (ambulatórias e hospitalares) do setor público e privado, restando ao governo federal as funções relativas ao financiamento; (ii) transferir aos Municípios a maior parte dos atendimentos básicos em saúde e (iii) transferir ao Estados e Municípios as atividades de vigilância sanitária e epidemiológica (8).

A existência de um SUS em cada esfera de governo é reconhecida, mas com atribuições diferentes e não comuns, tampouco solidárias. Em cumprimento à diretriz da descentralização, competiria aos Municípios, isolados ou organizados em regiões de saúde, a prestação direta de serviços públicos de saúde. Entretanto, como os custos dos serviços de saúde são vultosos e recursos municipais são quase sempre escassos, a CRFB, prestigiando o federalismo cooperativo (9), determinou, a prestação indireta de serviços públicos de saúde como responsabilidade da União e dos Estados, na forma de cooperação técnica e financeira aos Municípios e na execução suplementar ou complementar de algumas ações e serviços, conforme especificado no artigo 16, inciso XV, e artigo 17, incisos I, III, IV, VIII, XI e XII, da Lei 8.080/90 (4).

Argumenta-se, também, que a Lei no 8.080/90 (4), lei ordinária elaborada dentro da competência legislativa concorrente dos entes federativos, ao definir as normas gerais e diretrizes do SUS, não atribuiu e nem poderia fazê-lo, por ausência de permissão constitucional, a possibilidade de prestação direta de todas as ações e serviços públicos de saúde pela União e pelos Estados.

Analisando o art. 16 da Lei no 8.080/90 (4), observa-se que foram atribuídas à União, em quase todos os seus incisos, as competências de gestão e organização do SUS. Tais funções são manifestadas nos verbos e expressões elencadas em cada inciso, tais como: 
"formular, avaliar e apoiar" (I); "definir e coordenar" (III); "participar da definição de normas" (IV e V); "estabelecer critérios, parâmetros e métodos" (VIII); "promover articulação" (IX); formular, avaliar, elaborar normas (X e XIV); "normatizar e coordenar nacionalmente" (XVI); elaborar o Planejamento Estratégico Nacional no âmbito do SUS (XVIII).

O referido dispositivo legal permite a participação da União na implementação de políticas públicas de saneamento básico e de condições do meio ambiente e do trabalho (inciso II e alíneas). Em outras situações, estabelece, excepcionalmente, a execução direta de algumas ações de saúde, tais como, de vigilância epidemiológica e sanitária (inciso VI e VII e § único).

Da mesma forma, 0 art. 17 da Lei № 8.080/90 (4) disciplina que cabe aos Estados promover a descentralização dos serviços e das ações de saúde (inciso I) para os Municípios, bem como prestar-Ihes apoio técnico e financeiro (inciso III). A lei é expressa ainda ao determinar que a execução direta do serviço de saúde pelos Estados é supletiva, isto é, complementar (incisos III e IV). Aos Estados também são atribuídas as funções de gestão e coordenação, especialmente das redes hierarquizadas e das regiões de saúde (incisos II e IX).

Por fim, a Lei o 8.080/90 (4) não deixa dúvidas que incumbe aos entes locais (Municípios e Distrito Federal), como regra, a prestação direta de ações e serviços públicos de saúde, conforme art. 18, inciso I: "planejar, organizar, controlar e avaliar as ações e os serviços de saúde e gerir e executar os serviços públicos de saúde". Tal disciplina está em perfeita consonância com o princípio da predominância do interesse que rege as normas constitucionais de competências dos entes federados.

Em resumo, argumenta-se, que inexiste responsabilidade solidária para prestação de todas ações e serviços de saúde pelos entes federados sob os seguintes fundamentos: i) a competência administrativa comum estabelecida no inciso II do art. 23 (2) diz respeito aos cuidados da saúde da pessoa portadora de deficiência e não de todas as pessoas, ponto ainda pouco explorado pela doutrina; ii) a CRFB estabelece, expressamente, a competência administrativa exclusiva dos Municípios, para prestar, direta e predominantemente, segundo o interesse local, "serviços de atendimento à saúde da população" (art. 30, inciso VII) (2); e iii) a União e os Estados prestam ações e serviços de saúde de forma indireta, (a) por meio da cooperação técnica e financeira aos Municípios; (b) através do exercício de atribuições 
de gestão e coordenação do SUS em âmbito nacional e estadual; (c) mediante a elaboração de normas gerais e diretrizes norteadoras do SUS (art. 24, XII) decorrentes de suas competências legislativas concorrentes; e (d) pela prestação complementar de algumas ações e serviços elencados na Lei no 8.080/90 (artigo 16, inciso XV, e artigo 17, incisos I, III, IV, VIII, XI e XII) (4).

Competência administrativa comum e responsabilidade solidária da União, Estados, DF e Municípios para a prestação de ações e serviços de saúde

Em caminho contrário ao exposto acima, afirma-se que há sim competência administrativa comum e responsabilidade solidária dos entes federativos para a execução direta de ações e serviços de saúde, ainda que haja a preponderância do papel dos Municípios no SUS. Nesse sentido, qualquer um dos entes federados pode ser acionado em juízo para prestar ações e serviços de saúde e, caso apenas um dos entes seja demandado, poderá promover o chamamento em juízo dos demais, para divisão compartilhada da responsabilidade solidária (10).

O primeiro ponto a ser analisado refere-se à competência administrativa comum de todos os entes federativos em cuidar da saúde e assistência pública, da proteção e garantia das pessoas portadoras de deficiência (inciso II do art. 23) (2). Uma leitura apressada pode levar à conclusão que a referida competência administrativa restringe-se apenas aos cuidados da saúde das "pessoas com deficiência".

Observa-se, contudo, que, quando tratou da competência concorrente da União, Estados e DF (art. 24) para legislar, a CRFB destacou, em incisos próprios, "previdência social, proteção e defesa da saúde" (XII) e a "proteção e integração social das pessoas portadoras de deficiência" (XIV) (2). Trata-se, portanto, de mera técnica legislativa que, ao disciplinar as competências administrativas comuns dos entes federados, contemplou os temas "defesa da saúde" e "proteção da pessoa com deficiência" no mesmo dispositivo constitucional (art. 23, II), mas que, ao definir as competências legislativas concorrentes desses mesmos entes, separou tais temas em normas constitucionais distintas, mas que se complementam (art. 24, incisos XII e XIV) (20.

Além disso, assim como existe um paralelismo entre as competências administrativas exclusivas da União, previstas no art. 21, e suas competências legislativas privativas, constantes do art. 22, há também essa mesma relação de conformidade entre as 
competências administrativas comuns da União, Estados, DF e Municípios (art. 23) e as competências legislativas concorrentes da União, Estados e DF (art. 24) e, ainda, com as competências legislativas suplementares dos Municípios (art. 30, inciso II) (2).

Compreende-se, dessa forma, que a CRFB (20 estabelece como dever do Estado (União, Estados, DF e Municípios) a proteção e defesa da saúde, por meio de atribuições administrativas comuns e competências legislativas concorrentes. Entretanto, como evidencia Suely Dallari, não se trata de sobreposições e repetições de "ações paralelas por todas as esferas de governo, mas sim, multiplicar a responsabilidade em relação a determinadas matérias" (11), mediante estratégias e ações de cooperação que visem o equilíbrio do desenvolvimento e do bem-estar em âmbito nacional (art. 23, § único) (2).

Como já vimos, a repartição de competências constitucionais é orientada pelo princípio da predominância do interesse (1), competindo à União executar ações e serviços de saúde de interesses nacionais; aos Estados e DF, cabe a prestação de serviços de saúde de âmbito regional e, finalmente, aos Municípios, o planejamento e execução de ações e serviços de saúde de interesse local ou intermunicipal.

Além de executar diretamente algumas ações e serviços de saúde expressamente previstos na CRFB e em leis específicas, tais como a Lei no 8.080/90 (4) e Lei nํ 8.142/90 (5), caberá a União, aos Estados e ao DF exercer atribuições de gestão e de coordenação, bem como de cooperação técnica e financeira (Lei Complementar nํ 141/90) (12), visando a municipalização das demais ações e serviços públicos de saúde, para atendimento da população local (art. 30, inciso VII) (2).

Para conhecermos melhor as interpretações possíveis e razoáveis dos dispositivos constitucionais e legais acima mencionados, tornar-se imperiosa a análise da evolução das decisões proferidas pelo Poder Judiciário, especialmente pelo STF, que deterá a prerrogativa de definir os parâmetros da responsabilidade sanitária da União, Estados, Distrito Federal e Municípios.

\section{Posicionamento do Supremo Tribunal Federal sobre a responsabilidade dos entes da Federação na execução de ações e serviços de saúde}

Como julgamento paradigma, em 17 de março de 2010, o STF, na suspensão de Tutela Antecipada no 175 (13), ao interpretar o dever do Estado de prestar serviços de saúde, 
decidiu, por unanimidade e nos termos do voto do relator, Ministro Gilmar Mendes, que a CRFB estabeleceu a competência administrativa comum e a responsabilidade solidária dos entes da Federação para cuidar da saúde (art. 23, II), na seguinte forma:

União, Estados, Distrito Federal e Municípios são responsáveis solidários pela saúde, tanto do indivíduo quanto da coletividade e, dessa forma, são legitimados passivos nas demandas cuja causa de pedir é a negativa, pelo SUS (seja pelo gestor municipal, estadual ou federal), de prestações na área de saúde. O fato de o Sistema Único de Saúde ter descentralizado os serviços e conjugado os recursos financeiros dos entes da Federação, com o objetivo de aumentar a qualidade e o acesso aos serviços de saúde, apenas reforça a obrigação solidária e subsidiária entre eles. As ações e os serviços de saúde são de relevância pública, integrantes de uma rede regionalizada e hierarquizada, segundo o critério da subsidiariedade, e constituem um sistema único (13).

A jurisprudência do STF se firmou no sentido de que existe responsabilidade solidária dos entes federativos para execução de ações e serviços de saúde indispensáveis à proteção e concretização do direito à saúde, tais como o fornecimento gratuito de tratamentos e medicamentos para pessoas hipossuficientes.

Nesse sentido, vejamos as seguintes ementas:

EMENTA: DIREITO CONSTITUCIONAL. DIREITO Á SAÚDE. AGRAVO REGIMENTAL EM RECURSO EXTRAORDINÁRIO. MEDICAMENTO. FORNECIMENTO. OBRIGAÇÃO SOLIDÁRIA. ENTES FEDERATIVOS. PRECEDENTES. 1. A jurisprudência do Supremo Tribunal Federal é firme no sentido de que o fornecimento gratuito de tratamentos e medicamentos necessários à saúde de pessoas hipossuficientes é obrigação solidária de todos os entes federativos, podendo ser pleiteado de qualquer deles, União, Estados, Distrito Federal ou Municípios (Tema 793). 2. Agravo a que se nega provimento (14).

EMENTA: (...) 3. RESPONSABILIDADE SOLIDÁRIA DAS PESSOAS POLITICAS QUE INTEGRAM O ESTADO FEDERAL BRASILEIRO, NO CONTEXTO DO SISTEMA ÚNICO DE SAÚDE (SUS) - COMPETÊNCIA COMUM DOS ENTES FEDERADOS (UNIÃO, ESTADOSMEMBROS, DISTRITO FEDERAL E MUNICÍPIOS) EM TEMA DE PROTEÇÃO E ASSISTÊNCIA À SAÚDE PÚBLICA E/OU INDIVIDUAL (CF, ART. 23, II). DETERMINAÇÃO CONSTITUCIONAL QUE, AO INSTITUIR O DEVER ESTATAL DE DESENVOLVER AÇÕES E DE PRESTAR SERVIÇOS DE SAÚDE, TORNA AS PESSOAS POLÍTICAS RESPONSÁVEIS SOLIDÁRIAS PELA CONCRETIZAÇÃO DE TAIS OBRIGAÇÕES JURÍDICAS, O QUE LHES CONFERE LEGITIMAÇÃO PASSIVA "AD CAUSAM" NAS DEMANDAS MOTIVADAS POR RECUSA DE ATENDIMENTO NO ÂMBITO DO SUS - CONSEQUENTE POSSIBILIDADE DE AJUIZAMENTO DA AÇÃO CONTRA UM, ALGUNS OU TODOS OS 


\section{ENTES ESTATAIS - PRECEDENTES - RECURSO DE AGRAVO IMPROVIDO (15).}

Percebe-se, portanto, que o STF manteve-se fiel às teses fixadas na STA o 175 (13), a saber: i) responsabilidade comum e solidária da União, Estados, Distrito Federal e Municípios para execução de ações e serviços de saúde imprescindíveis à proteção e concretização do direito à saúde, podendo quaisquer uns desses entes ser acionados em juízo; ii) a diretriz constitucional da descentralização dos serviços e cooperação financeira entre os entes da Federação tem como objetivo o aumento da qualidade e 0 acesso aos serviços de saúde, o que reafirma a obrigação solidária e subsidiária entre eles: e iii) as ações e os serviços de saúde são de relevância pública, constituem um sistema único e integram uma rede regionalizada e hierarquizada, segundo o critério da subsidiariedade.

Percebe-se, contudo, que o STF nunca avançou na análise mais pormenorizada da distinção entre solidariedade e subsidiariedade na responsabilização sanitária de cada ente federado (16). Tampouco correlacionou, de forma mais objetiva, esses critérios aos mandamentos constitucionais da descentralização, regionalização e hierarquização. Nesse sentido, Dresch e Neto (16) afirmam que:

Sem embargo do mérito das decisões da Suprema Corte sobre o tema e as consequências jurídicas dali decorrentes, é importante consignar que, a partir da Lei no 12.401/2011 - que alterou significativamente a estrutura do Sistema Único de Saúde (regulado pela Lei no 8080/90) -, já não é mais possível sustentar-se a existência de plena solidariedade entre os entes políticos para responder todas e quaisquer ações judiciais onde se busque o direito prestacional à saúde pública (16).

Recentemente, o STF perdeu mais uma oportunidade de refinar os critérios para aplicação da responsabilidade sanitária aos entes da Federação, ao julgar o RE no 855.178 (17), com situações fáticas e jurídicas a seguir expressas:

Trata-se de recurso extraordinário interposto pela UNIÃO, com fulcro no art. 102, III, a, da Constituição da República, em face de acórdão prolatado pelo Tribunal Regional Federal da 5 ${ }^{\text {a }}$ Região (...) Noticiam os autos que a autora ingressou com esta ação visando à obtenção da medicação de nome BOSENTANA (TRACLEEER $62,5 \mathrm{mg} / 125 \mathrm{mg}$ ), tendo logrado êxito já em sede de antecipação de tutela deferida em audiência realizada em 19/10/2009, que determinou a aquisição do medicamento pelo Estado de Sergipe e o cofinanciamento do valor pela União, em percentual correspondente a $50 \%$ (cinquenta por cento). O Estado de Sergipe, em cumprimento à referida 
decisão, procedeu à entrega do medicamento em 23/11/2009, através de sua Secretaria da Saúde. O juízo a quo ratificou a tutela antecipatória na sentença, e aproximadamente dois meses após esta sobreveio o falecimento da autora, o que provocou a cessação da obrigação de fazer. Contudo, persistiu o inconformismo da União quanto à ordem de ressarcimento do custeio do medicamento ao Estado de Sergipe. Em sede de apelação, o Tribunal Regional Federal da 5 ${ }^{\mathbf{a}}$ Região entendeu que o dever de prestar assistência à saúde é compartilhado entre a União, os Estados membros e os Municípios, e que a distribuição de atribuições entre os entes federativos por normas infraconstitucionais não elide a responsabilidade solidária imposta constitucionalmente, nos termos da ementa acima transcrita. Opostos embargos de declaração, restaram rejeitados. Irresignada, a recorrente interpôs o presente recurso extraordinário. Em suas razões recursais, sustenta a preliminar de repercussão geral e, no mérito, alega violação aos artigos 2o e 198 da CRFB/88. Argumenta, em suma, a ilegitimidade da UNIÃO para figurar no polo passivo da demanda, alegando que o SUS é guiado pelo princípio da descentralização e que a obrigação de fornecer e custear os medicamentos seria de incumbência exclusiva dos órgãos locais (17).

Ao reconhecer a existência de repercussão geral da questão constitucional discutida no RE, o Plenário virtual confirmou a jurisprudência dominante da Corte no sentido de que os entes da Federação, isolados ou conjuntamente, respondem de forma solidária pelo dever de efetivar o direito à saúde em favor dos necessitados. Tendo em vista que a decisão do Plenário virtual não foi unânime, a União recorreu por meio de embargos para levar o caso a julgamento pelo Plenário físico.

No julgamento presencial, em 22 de maio de 2019, por maioria, os ministros acompanharam a divergência iniciada pelo Ministro Edson Fachin para rejeitar os embargos e fixar tese de repercussão geral, sendo seguido pelos Ministros Ricardo Lewandowski, Rosa Weber, Cármen Lúcia e Gilmar Mendes e pelo Ministro Marco Aurélio somente quanto à rejeição dos embargos. Restaram vencidos os Ministros Luiz Fux (relator), Alexandre de Moraes, Luís Roberto Barroso e o presidente do STF, Ministro Dias Toffoli, que acolheram parcialmente os embargos a fim de prestar esclarecimentos e avançar na matéria para distinguir a solidariedade da subsidiariedade. Ao final, o Tribunal, por maioria, fixou a seguinte tese de repercussão geral (Tema 793):

Os entes da federação, em decorrência da competência comum, são solidariamente responsáveis nas demandas prestacionais na área da saúde, e diante dos critérios constitucionais de descentralização e hierarquização, compete à autoridade judicial direcionar o cumprimento conforme as regras 
de repartição de competências e determinar o ressarcimento a quem suportou o ônus financeiro (18).

Verifica-se, dessa forma, que o STF, apesar de mencionar os critérios constitucionais da descentralização e hierarquização, bem como as regras de repartição das competências constitucionais, estabeleceu que os entes federados são solidariamente responsáveis, podendo ser demandados em conjunto e que aquele ente que suportar o ônus financeiro dos serviços de saúde deverá ser ressarcido pela cota parte dos demais entes.

Em outras palavras, se a responsabilidade é solidária e todos os entes podem ser levados a juízo indistintamente, de nada valem as diretrizes constitucionais da descentralização, hierarquização e regionalização, já que caberá somente à parte autora da ação individual ou coletiva escolher quem deverá cobrado pelas ações e serviços de saúde requeridos.

Caminharia melhor o STF se aprofundasse a discussão para, conforme as diretrizes da descentralização, regionalização e hierarquização, firmasse a responsabilidade subsidiária dos entes federativos para a prestação de ações e serviços de saúde. Nessa linha, imperioso analisar, ainda que inicialmente, as definições e conteúdos jurídicos desses parâmetros legais, o que será apreciado no próximo tópico.

\section{As diretrizes da descentralização, regionalização e hierarquização como critérios objetivos da responsabilidade sanitária solidária e/ou subsidiária dos entes da Federação}

A repartição constitucional de competências legislativas e administrativas dos entes federativos, os princípios do acesso universal, integral e igualitário às ações e serviços de saúde, bem como as diretrizes da descentralização, regionalização e hierarquização constituem o modelo de governança do SUS, conforme estabelecido na CRFB (2), Lei no 8.080/90 (4) e Lei no 8.142/90. (5)

O mandamento constitucional que estabelece a descentralização é uma norma de organização e significa a atribuição de responsabilidades e repartição de competências entre a União, os Estados, o Distrito Federal e os Municípios, para legislar concorrentemente sobre a proteção e a defesa da saúde (art. 24, XII) (2), bem como para organização desses entes, em conjunto ou separadamente, visando o planejamento e execução de políticas públicas 
econômicas e sociais destinadas à proteção e concretização do direito à saúde (art. 23, II) (2).

Essa organização institucional se dará no âmbito de cada esfera de governo federal, estadual, distrital e municipal, bem como por meio das Comissões Intergestores Tripartite (CIT), Bipartite (CIB) e Regional (CIR), reconhecidas pela Lei no 12.466, de 2011, como inovação gerencial na política pública de saúde. Constituem-se como foros permanentes de negociação, articulação e decisão entre os gestores nos aspectos operacionais e na construção de pactos nacionais, estaduais e regionais no SUS (19).

Além das Comissões Intergestores, a Lei no 12.466/11 (19) também inovou ao declarar como de utilidade pública e de relevante função social o Conselho Nacional de Secretários de Saúde (Conass) e o Conselho Nacional de Secretarias Municipais de Saúde (Conasems), reconhecendo-os como entidades representativas dos entes estaduais e municipais para tratar de matérias referentes à saúde. O Conass e o Conasems recebem recursos do orçamento geral da União por meio do Fundo Nacional de Saúde, para auxiliar no custeio de suas despesas institucionais, podendo ainda celebrar convênios com a União. A referida lei também reconhece os Conselhos de Secretarias Municipais de Saúde (Cosems) como entidades que representam os entes municipais, no âmbito estadual, para tratar de matérias referentes à saúde, desde que vinculados institucionalmente ao Conasems, na forma que dispuserem seus estatutos.

Conforme já mencionado em tópico anterior, a União e os Estados podem promover, mediante cooperação técnica e financeira (art. 30, VII), a municipalização da saúde (20), transferindo aos Municípios poderes de gestão do SUS, para elaborar e prestar políticas de saúde à sua população local. Os Municípios podem, ainda, ao assumirem a gestão descentralizada do SUS, organizarem-se na forma de consórcios administrativos intermunicipais de saúde (distritos sanitários), integrando e manejando recursos entre si e articulando práticas e técnicas para a cobertura total das ações de saúde na área regionalizada (art. 10, da Lei no 8.080/90 (4) e art. 3ํ, parágrafo 3ํ, da Lei no 8.142/90). (5)

Além da municipalização, a descentralização administrativa pode se efetivar na forma de regionalização, que consiste na formação de regiões de saúde, como instrumento de ordenação territorial da prestação dos serviços de saúde, garantindo o cumprimento dos princípios constitucionais de universalidade do acesso, igualdade e integralidade do cuidado. 
O Decreto n 7.508, de 2011 (21), que regulamenta a Lei no 8.080/90 (4), estabelece que a região de saúde é um espaço geográfico contínuo, construído por agrupamentos de Municípios limítrofes, delimitado a partir de identidades culturais, econômicas e sociais e de redes de comunicação e infraestrutura de transportes compartilhados, com a finalidade de integrar a organização, o planejamento e a execução de ações e serviços de saúde.

As regiões de saúde serão instituídas pelo Estado, em articulação com os Municípios, respeitadas as diretrizes gerais pactuadas na CIT. Poderão ser instituídas regiões de saúde interestaduais, compostas por Municípios limítrofes, por ato conjunto dos respectivos Estados em articulação com os Municípios e a sua instituição observará cronograma pactuado nas Comissões Intergestores. Já a instituição das regiões de saúde situadas em áreas de fronteira com outros países deverá respeitar as normas que regem as relações internacionais.

Essas regiões de saúde devem conter, no mínimo, ações e serviços de atenção primária, urgência e emergência, atenção psicossocial, atenção ambulatorial especializada e hospitalar, e vigilância em saúde. As regiões de saúde serão referência para as transferências de recursos entre os entes federativos, de modo que as responsabilidades de cada ente na prestação de serviços na região devem estar bem definidas e pactuadas tanto na $\mathrm{CIR}$, quanto na $\mathrm{CIB}$, e os planos e as metas regionais resultantes das pactuações intermunicipais devem promover a equidade interregional. Por sua vez, a Lei Complementar no 141, de 2012 (12), acrescenta que essas transferências de recursos entre entes devem se dar preferencialmente, de forma regular e automática, em conformidade com os critérios de transferência aprovados pelo respectivo Conselho de Saúde.

Os entes federativos definirão, em relação às regiões de saúde, seus limites geográficos, população usuária das ações e dos serviços, rol de ações e serviços que serão ofertados e respectivas responsabilidades, critérios de acessibilidade e escala para conformação dos serviços. Tais elementos deverão fazer parte do Contrato Organizativo de Ação Pública da Saúde (Coap), nos termos do Capítulo V, do Decreto no 7.508/11. (21)

Outro importante parâmetro de aferição da responsabilidade de cada ente da Federação no SUS diz respeito às redes de atenção à saúde, como definição de espaços territoriais onde se cumprirá o mandamento constitucional da hierarquização das ações e serviços de saúde. Segundo Dallari (220, as políticas de proteção sanitária foram 
hierarquizadas em três formas de prevenção:

a primária, que se preocupa com a eliminação das causas e condições de aparecimento das doenças, agindo sobre o ambiente (segurança nas estradas, saneamento básico, por exemplo) ou sobre o comportamento individual (exercício e dieta, por exemplo); a secundária ou prevenção específica, que busca impedir o aparecimento de doença determinada, por meio da vacinação, dos controles de saúde, da despistagem; e a terciária, que visa limitar a prevalência de incapacidades crônicas ou de recidivas (22).

O Decreto no 7.508/11 (21) define a Rede de Atenção à Saúde (RAS) como o conjunto de ações e serviços de saúde articulados em níveis de complexidade crescente, que objetiva garantir a integralidade da assistência à saúde. As RAS estarão compreendidas no âmbito de uma região de saúde, ou de várias delas, em consonância com diretrizes pactuadas nas Comissões Intergestores, sendo que as portas de entrada às ações e aos serviços de saúde nessas redes serão os serviços de atenção primária, de atenção de urgência e emergência, de atenção psicossocial, e especiais de acesso aberto. Dependendo das características da região de saúde e, após pactuação nas Comissões Intergestores, os entes federativos poderão criar portas de entrada.

Colocados os conceitos dos termos descentralização, regionalização e hierarquização, bem como seus conteúdos jurídicos, resta analisar como tais parâmetros podem influenciar na natureza da responsabilidade sanitária de cada ente da Federação.

Os art. 264, 275 e 283 do Código Civil definem responsabilidade solidária da seguinte forma:

Art. 264. Há solidariedade, quando na mesma obrigação concorre mais de um credor, ou mais de um devedor, cada um com direito, ou obrigado, à dívida toda.

Art. 275. O credor tem direito a exigir e receber de um ou de alguns dos devedores, parcial ou totalmente, a dívida comum; se o pagamento tiver sido parcial, todos os demais devedores continuam obrigados solidariamente pelo resto.

Art. 283. O devedor que satisfez a dívida por inteiro tem direito a exigir de cada um dos co-devedores a sua quota, dividindo-se igualmente por todos a do insolvente, se o houver, presumindo-se iguais, no débito, as partes de todos os co-devedores. Parágrafo único. Não importará renúncia da solidariedade a propositura de ação pelo credor contra um ou alguns dos devedores (23).

Observa-se que o STF decidiu conforme os dispositivos acima, reafirmando que todos os entes da Federação têm obrigação sanitária solidária, ou seja, são corresponsáveis pela 
prestação de todos os tipos de ações e serviços de saúde. Conforme tese estabelecida no julgamento do RE no 855.178 (18), competirá à autoridade judicial direcionar o cumprimento conforme as regras de repartição de competências e determinar o ressarcimento a quem suportou o ônus financeiro. No caso, a União se viu obrigada a repassar o custo de $50 \%$ (cinquenta por cento) do valor do medicamento fornecido à parte requerente, mediante ressarcimento ao Estado de Sergipe, que arcou com o valor integral do medicamento.

Apesar de fazer menção aos critérios constitucionais da descentralização, regionalização e hierarquização, o STF reafirmou que tais diretrizes, na prática, não surtirão nenhum efeito na responsabilidade dos entes federados, já que todos podem ser obrigados a fornecer, isolada ou conjuntamente, as ações e serviços de saúde.

Para o STF, a responsabilidade solidária é uma decorrência da fixação da competência constitucional comum dos entes federados. Entretanto, pode-se afirmar que competência administrativa comum não exclui hipóteses em que haverá: i) a responsabilidade exclusiva de um único ente; ou ii) responsabilidade subsidiária entre eles.

Na primeira hipótese, podemos citar a situação em que um ente da Federação tem, por determinação infraconstitucional, competência administrativa exclusiva em matéria de saúde. É o que ocorre no caso no registro de novos medicamentos: conforme art. 12 da Lei no 6.360/75 (24), nenhum produto, inclusive os importados, poderá ser industrializado, exposto à venda ou entregue ao consumo antes de registrado no Ministério da Saúde. Caberá à Anvisa conceder registros de produtos, segundo as normas de sua área de atuação (art. 7ํㅜㄹ inciso IX, Lei no 9.782/99) (25).

Nesse caso, somente poderá ser demanda judicialmente a União, já que é a única responsável conceder registro de algum medicamento. Esse entendimento restou assentado no julgamento do RE no 657718 (26), Ministro Relator Roberto Barroso, fixando a tese que as ações que demandem fornecimento de medicamentos sem registro na Anvisa deverão necessariamente ser propostas em face da União.

Na segunda hipótese, haverá responsabilidade subsidiária dos entes federativos quando, por critérios de descentralização, regionalização e hierarquização, houver pactuação de quem, como, quando e onde devem ser prestadas as ações e serviços de atenção à saúde. Ou seja, uma vez definida a competência sanitária específica por meio de pactuação entre gestores, tal atribuição deverá ser respeitada para efeito de fixação da 
legitimidade passiva da demanda judicial. Dessa forma, somente no caso de descumprimento da obrigação pelo ente principal responsável, os demais entes poderão ser acionados, em decorrência da obrigação subsidiária. Nesse sentido, vale lembrar a lição de Dresch (9), no sentido de que:

\begin{abstract}
A solidariedade instituída no art. 23, II, da Constituição Federal tem natureza apenas institucional, impondo à União, aos Estados-membros, ao Distrito Federal e aos Municípios a responsabilidade pela organização do sistema, com a instituição de uma rede regionalizada, hierarquizada e descentralizada, com direção única em cada esfera de governo, para alcançar o atendimento integral (CF, art. 198). Uma vez criada a rede de atenção com a repartição de competência (SUS) haverá o fracionamento da solidariedade, que se transforma em responsabilidade subsidiária (9).
\end{abstract}

Nos debates do julgamento do RE n 855.178 (18), o Ministro Fux decidiu reajustar seu voto e acolher parcialmente os embargos a fim de prestar esclarecimentos. Sua posição foi seguida pelos Ministros Alexandre de Moraes, Luís Roberto Barroso e pelo Presidente do STF, Ministro Dias Toffoli, que avançaram na matéria para distinguir a solidariedade da subsidiariedade. Eles salientaram que a responsabilidade solidária permite que uma pessoa peça para qualquer um dos entes federados, indistintamente, o custeio do medicamento. $\mathrm{Na}$ subsidiariedade, a ação deve ser proposta especificamente contra o ente responsável pelo fornecimento do remédio. Os ministros que acompanharam essa vertente entendem que a subsidiariedade é melhor para o sistema e que a solidariedade não deve ser aplicada ao caso.

\title{
Considerações finais
}

A interpretação dos dispositivos constitucionais que fixam a repartição de competências em matéria de saúde é de extrema complexidade, uma vez que envolve a análise por parte do sistema de Justiça de diversos conceitos e termos específicos do sistema de saúde, tais como, descentralização, regionalização e hierarquização das ações e serviços que integram o SUS.

A maioria da doutrina e da jurisprudência pátria entende que a competência administrativa, estabelecida no art. 23, inciso II, é comum e, por consequência, solidária, ou seja, todos os entes federativos podem ser demandados judicialmente, em igualdade de condições, para realização de ações e serviços de saúde, tais como, fornecimento de medicamentos ou de tratamentos diversos. 
A dificuldade de análise de conceitos e termos próprios do sistema de saúde não pode se transformar um argumento instransponível no estabelecimento de critérios objetivos para a fixação da natureza da responsabilidade de cada ente federativo na execução de ações e serviços de saúde. Os recentes julgados do STF, especialmente o RE nํ855.178, mostram que ainda há um longo caminho a ser percorrido, uma vez que a maioria da Corte optou pela interpretação consolidada no histórico jurisprudencial, que não enfrenta a normativa infralegal, definindo como solidária a responsabilidade sanitária dos entes da Federação.

É preciso que a jurisprudência de nossa Corte Constitucional evolua para analisar mais detidamente o modelo de governança do SUS, constituído por regras infraconstitucionais próprias, que trazem a autonomia dos entes federados para disciplinar suas atribuições na proteção e concretização do direito à saúde.

Estabelecidas por meio das comissões intergestores as regras pormenorizadas das competências e das responsabilidades sanitárias de cada ente federado, segundo critérios de descentralização, regionalização e hierarquização, passam a vincular a atuação do Poder Judiciário na interpretação das normas constitucionais e infraconstitucionais para fixação das obrigações de cada ente, na forma de responsabilidade subsidiária, bem como delimitam a competência processual para julgamentos das demandas judiciais.

\section{Referências}

1. Barroso LR. Saneamento básico: competências constitucionais da União, Estados e Municípios. Disponível em: https://www2.senado.leg.br/bdsf/bitstream/handle/id/762/R15319.pdf?sequence $=4$ (Acesso em 05.02.19)

2. Brasil. Constituição da República Federativa do Brasil, 8 de outubro de 1998. Disponível em: http://www.planalto.gov.br/ccivil_03/constituicao/constituicao.htm [Acesso em 05.02.2019]

3. Moraes A. Competências administrativas e legislativas para vigilância sanitária de alimentos. Disponível em: http://www.pge.sp.gov.br/centrodeestudos/revistaspge/Revista \%20PGE\%2053.pdf\#page=233 [Acesso em 05.02.19].

4. Brasil. Lei no 8.080/90, de 19 de setembro de 1990. Disponível em: http://www.planalto.gov.br/ccivil_03/leis/l8080.htm [Acesso em 06.02.2019].

5. Brasil. Lei no 8.142, de 28 de dezembro. Disponível em: http://www.planalto.gov.br/ccivil_03/leis/L8142.htm [Acesso em 06.02.2019]. 
6. Almeida FDM. Competências na Constituição de 1988. São Paulo. Atlas, 1991, p. 124.

7. Schwartz G. Gestão compartida sanitária no Brasil: possibilidade de efetivação do direito à saúde. A saúde sob os cuidados do direito. In: Schwartz G (Org). A saúde sob os cuidados do direito. Passo Fundo: UPF Ed., 2003. p. 146-147.

8. Arretche MTS. Estado Federativo e políticas sociais: determinantes de descentralização. Rio de Janeiro: Revan; São Paulo: FAPESP, 2000, p. 209.

9. Dresch R. Federalismo Solidário: a responsabilidade dos entes federativos na área de saúde. in: SANTOS, Lenir; TERRAZ, Fernanda (Org.). Judicialização da Saúde no Brasil. Campinas: Saberes, 2014. p. 25-57. Disponível em: http://www.tjmt.jus.br/INTRANET.ARQ/CMS/GrupoPaginas/126/1127/FEDERALISMOSOLIDARIO-A-RESPONSABILIDADE-DOS-ENTES-FEDERATIVOS-NA-\%C3\%81READA-SA\%C3\%9ADE.pdf [Acesso em: 02.ago.2019].

10. Freitas CLT. Judicialização da saúde, solidariedade e ressarcimento: destaques da posição dos estados frente à polarização de entendimentos. in: Santos L, Terrazas F. (Org.). Judicialização da Saúde no Brasil. Campinas: Saberes, 2014, p. 59-96.

11. Dallari SG. O papel dos municípios no desenvolvimento de políticas de saúde. Disponível em: https://www.scielosp.org/article/rsp/1991.v25n5/401-405/ [Acesso em 05.02.2019].

12. Brasil. Lei Complementar o 141, de 13 de janeiro de 2012. Disponível em: http://www.planalto.gov.br/ccivil_03/leis/LCP/Lcp141.htm [Acesso em 07.02.2019].

13. STF. Suspensão de Tutela Antecipada ํo 175 e outros processos. Ministro Gilmar Mendes. Disponível em: http://www.stf.jus.br/arquivo/cms/noticianoticiastt/anexo/sta175.pdf [Acesso em 24.07.2019].

14. Brasil. Supremo Tribunal Federal. Ag. Reg. No Recurso RE no 892.590. Agravante: Etelvina Maria Moura Castelo Branco. Agravada: União Federal. Relator: Min. Roberto Barroso. Rio Grande do Norte, 16 set 2016. Disponível em: http://portal.stf.jus.br/processos/downloadPeca.asp?id=310405723\&ext=.pdf [Acesso em 23.jul.2019].

15. Brasil. Supremo Tribunal Federal. ARE no 727864. AgR. Agravante: estado do Paraná. Agravado: Ministério Público do estado do Paraná. Relator: Min. Celso de Mello. Paraná, 04 nov 2014. Disponível em: http://portal.stf.jus.br/processos/downloadPeca.asp?id $=298071216 \&$ ext $=$.pdf [Acesso em 24.jul.2019].

16. Neto JPG, Dresch RL. A responsabilidade solidária e subsidiária dos entes políticos nas ações e serviços de saúde. Disponível em: http://www.tjmt.jus.br/INTRANET.

ARQ/CMS/GrupoPaginas/126/1127/A-RESPONSABILIDADE-SOLID\%C3\%81RIA-ESUBSIDI\%C3\%81RIA-DOS-ENTES-POL\%C3\%8DTICOS-NAS-A\%C3\%87\%C3\%95ES-ESERVI\%C3\%87OS-DE-SA\%C3\%9ADE.pdf [Acesso em 10.03.19]. 
17. Brasil. Supremo Tribunal Federal. RE o 855178. Recorrente: União. Recorrida: Maria Augusta da Cruz Santos. Relator: Min. Luiz Fux. Sergipe, 05 mar 2015. Disponível em: http://portal.stf.jus.br/processos/downloadPeca.asp?id=15319097113\&ext=.pdf [Acesso em 26.jul.2019].

18. Brasil. Supremo Tribunal Federal. RE no 855178. Recorrente: União. Recorrida: Maria Augusta da Cruz Santos. Relator: Min. Luiz Fux. Sergipe, 23 maio 2019. Disponível em: http://portal.stf.jus.br/processos/detalhe.asp?incidente=4678356 [Acesso em 2.ago.2019].

19. Brasil. Lei 12.466, de 24 de agosto de 2011. Disponível em: http://www.planalto.gov.br/ccivil_03/_Ato2011-2014/2011/Lei/L12466.htm [Acesso em 03.ago.2019].

20. Carvalho G. A saúde pública no Brasil. Disponível em: http://www.scielo.br/pdf/ea/ v27n78/02.pdf [Acesso em 15.03.19].

21. Brasil. Decreto no 7.508, de 28 de junho de 2011. Disponível em: http://www.planalto.gov.br/ccivil_03/_Ato2011-2014/2011/Decreto/D7508.htm [Acesso em 03.ago.2019].

22. Dallari SG, Nunes Júnior VS. Direito Sanitário. São Paulo: Verbatim, 2010.

23. Brasil. Lei $\mathrm{n}^{0}$ 10.406, de 10 de janeiro de 2002. Disponível em: http://www.planalto.gov.br/ccivil_03/leis/2002/110406.htm [Acesso em: 04.ago.2019].

24. Brasil. Lei o 6.350, de 23 de setembro de 1976. Disponível em: http://www.planalto.gov.br/ccivil_03/LEIS/L6360.htm [Acesso em 04.ago.2019].

25. Brasil. Lei oํ 9.782, de 26 de janeiro de 1999. Disponível em: http://www.planalto.gov.br/ccivil_03/LEIS/L9782.htm [Acesso em 05.ago.2019].

26. Brasil. Supremo Tribunal Federal. RE № 657718. Recorrente: Alcirene de Oliveira. Recorrido: Estado de Minas Gerais. Relator: Min. Roberto Barroso. Minas Gerais, 22 maio 2019. Disponível em: http://portal.stf.jus.br/processos/detalhe.asp?incidente=4143144 [Acesso em 4.ago.2019].

Como citar esse artigo:

Rey Filho M, Pereira SPD. As responsabilidades solidária e subsidiária no federalismo brasileiro: contextualização em matéria de saúde e posicionamento do Supremo Tribunal Federal. Cadernos Ibero-Americanos de Direito Sanitário. 2019 jul./set.; 8(3): 152-172.

http://dx.doi.org/10.17566/ciads.v8i3.574 